\title{
Evaluation of the test drive cycle conditions impact on exhaust emissions from an internal combustion engine
}

Test results of exhaust emission sensitivity to engine operating conditions from a vehicle with a compression ignition engine have been analyzed. These results were determined in driving tests: NEDC (New European Driving Cycle), RDE (Real Driving Emissions) and Malta, an original drive cycle developed at Poznan University of Technology. The tests in the NEDC and Malta cycles were carried out on the engine dynamometer in driving tests simulation conditions, while the RDE test was carried out in the real conditions of passenger car traffic. The mean exhaust emission test results of carbon monoxide, hydrocarbons, nitrogen oxides and carbon dioxide as well as the mean particle number in individual tests have been provided. A high sensitivity of the tested emission values to the changes in engine's operating conditions was found, both for static and dynamic conditions. The strongest impact of engine operating conditions was found for hydrocarbons emissions and the number of particles, followed by carbon monoxide, a smaller impact was found for nitrogen oxides and carbon dioxide. The largest differences in the values characterizing exhaust emissions were found for the NEDC test, which differed the most in dynamic engine operating conditions from other tests that closer resemble real driving conditions of vehicles.

Keywords: combustion engines, exhaust emissions, test drive cycles

\section{Introduction}

Fuel consumption and exhaust emissions are strongly dependent on the operating conditions of internal combustion engines, both static conditions and, above all, the dynamic conditions [2, 3, 6, 12-14]. Exhaust emissions showed a larger dependence on the internal combustion engines operating conditions than the fuel consumption values. Particularly high sensitivity of exhaust emissions to the internal combustion engines operating conditions can be seen for spark-ignition engines [2, 3, 6].

The car engines operating conditions are related to vehicle speed. Therefore, the ecological properties of automotive internal combustion engines are determined by each change in vehicle speed. It is visible in the exhaust emission test results in various test cycles.

Drive tests for exhaust emissions measurement from cars differ in their creation and properties, depending also on the testing method.

The main two methods of developing a test drive cycle include [5]:

- creating tests based on the synthesis of the speed curve in accordance with the assumed characteristics of the vehicle speed characteristics, such as mean speed, maximum speed, extreme values of accelerations, speed probability density etc., determined in empirical studies of car speed characteristics in their real operating conditions,

- creating tests in accordance with the principle of accurate simulation of the speed curve in the time domain based on recorded drive cycles of cars in their real operating conditions.

Examples of tests created by the first method include the tests: NEDC (New European Driving Cycle) and Japan Mode 10-11 [16]. The second method was used to design tests: FTP-75 (Federal Transient Procedure) and WLTC (Worldwide Harmonized Light Vehicles Test Cycle) [16].

Differences in parameters used to simulate different vehicle speed characteristics, e.g. urban and extra-urban driving, can be significant $[2-7,11,15]$. The difference in dynamic speed characteristic, whose implementation is done in individual tests, is particularly noticeable. Based on the analysis of drive tests the following pattern can be identified: tests created in accordance with the principle of accurate time domain simulation are more dynamic than tests developed using speed characteristic synthesis in accordance with assumed characteristics of the vehicle speed curve $[2,5]$. This can cause large differences in the exhaust emission results from internal combustion engines of vehicles tested in various drive cycles [2-7].

This publication presents the exhaust emission test results of a compression-ignition engine in a passenger car in various tests that differ in their creation method and properties.

\section{The aim, method, and test vehicle}

The aim of the research was to assess the sensitivity of exhaust emissions from an internal combustion engine on its operating conditions in various test cycles.

The tests used a passenger vehicle equipped with a compression-ignition engine. This was a 4-cylinder 1.3 JTD (MultiJet) turbocharged engine with a displacement of $1.3 \mathrm{dm}^{3}$, rated in the Euro 4 emission category. The car was a Fiat Idea with a mileage of $92,000 \mathrm{~km}$ (Fig. 1).

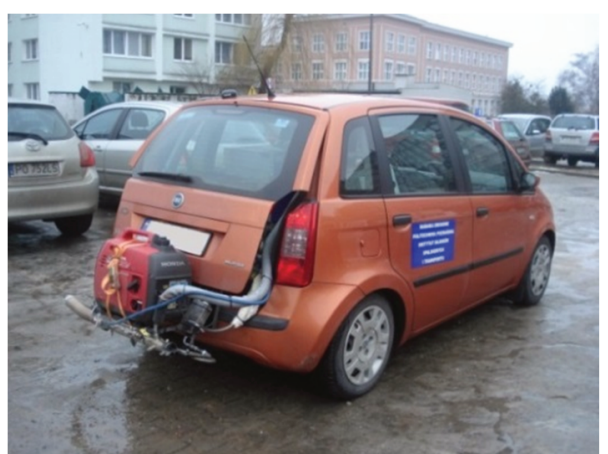

Fig. 1. Fiat Idea with mounted exhaust measuring apparatus [1] 
Latest generation engine was deliberately chosen for the tests due to the technical solutions used in it, in particular due to the exhaust emission values, so that it is possible to clearly verify the impact of the engine operating conditions on exhaust emissions.

The technical parameters of the test vehicle's engine have been presented in Table 1 [1].

Table 1. Compression-ignition 1.3 JTD (MultiJet) engine technical parameters [1]

\begin{tabular}{|l|c|}
\hline Fuel supply & Direct injection \\
\hline Displacement & $1300 \mathrm{~cm}^{3}$ \\
\hline Engine boost & $\begin{array}{c}\text { Turbocharger with set geometric } \\
\text { parameters }\end{array}$ \\
\hline Number of cylinders/valves & R4/8 \\
\hline $\begin{array}{l}\text { Injection system, maximum injection } \\
\text { pressure }\end{array}$ & Reservoir, $140 \mathrm{MPa}$ \\
\hline Maximum power at engine speed & $51 \mathrm{~kW} / 4000 \mathrm{rpm}$ \\
\hline Maximum torque at engine speed & $180 \mathrm{~N} \cdot \mathrm{m} / 1750 \mathrm{rpm}$ \\
\hline Oxidation reactor & Yes \\
\hline Particulate filter & No \\
\hline Vehicle curb weight & $1250 \mathrm{~kg}$ \\
\hline
\end{tabular}

The tests performer included:

- NEDC test simulated on an engine dynamometer (Fig. 2),

- Malta test simulated on an engine dynamometer (Fig. 3),

- RDE (Real Driving Emissions) tests of the vehicle; in the RDE test the analysis divided the cycle into parts: urban driving - RDE-U; rural driving RDE-R highway driving - RDE-H (Figs 4-7).

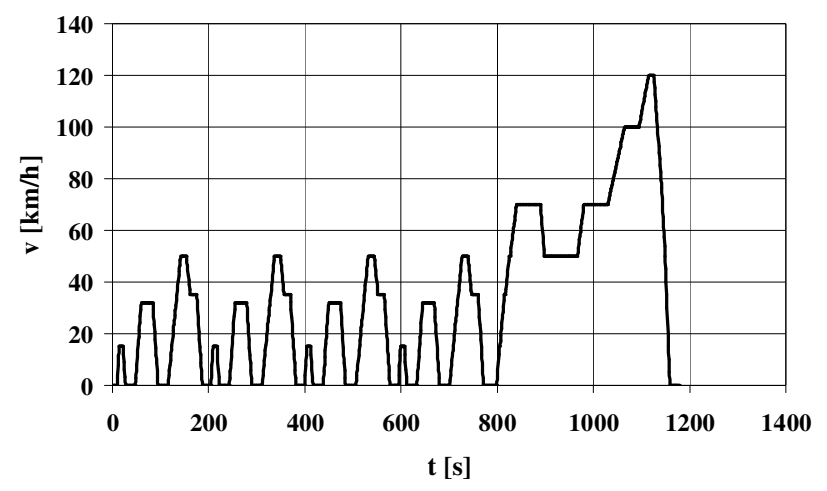

Fig. 2. Speed curve $-v$ in the NEDC test cycle

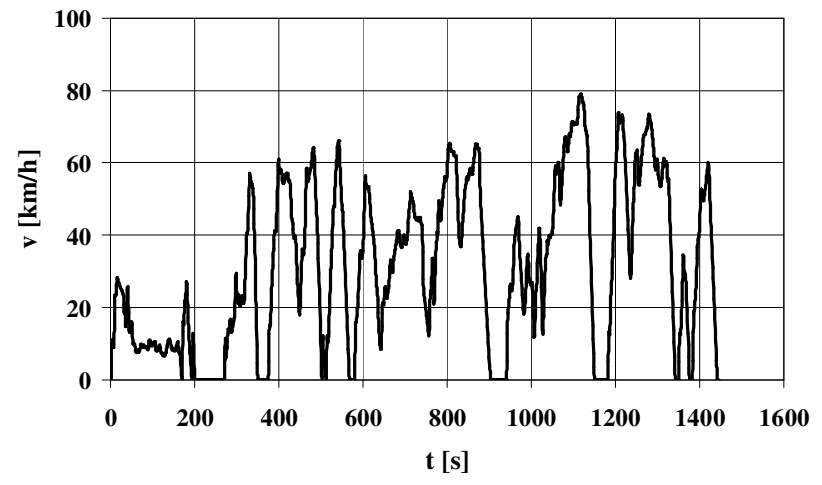

Fig. 3. Speed curve $-v$ in the Malta test cycle

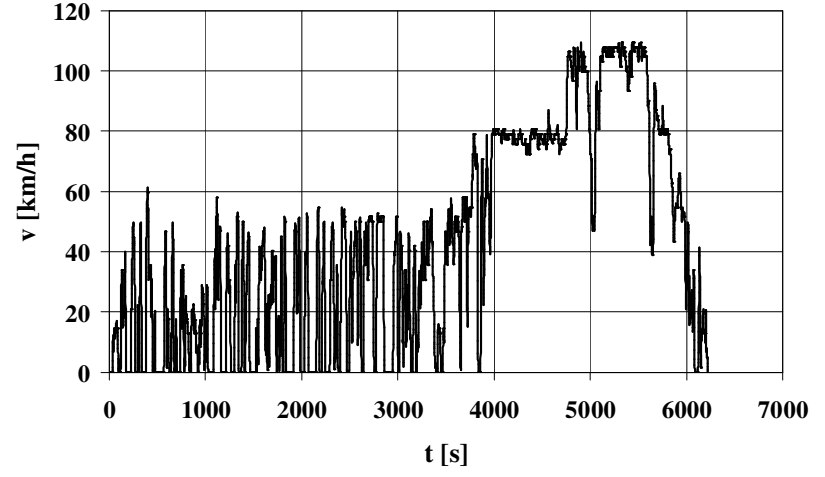

Fig. 4. Speed curve $-\mathrm{v}$ in the RDE test cycle performed with a Fiat Idea [1]

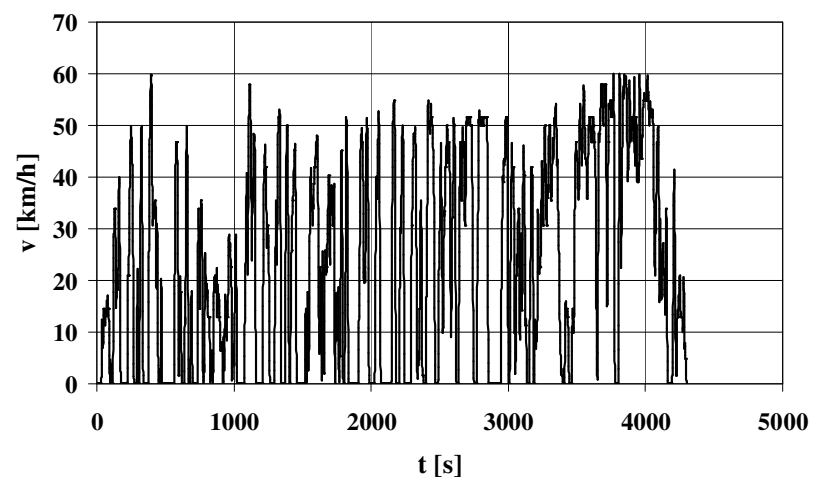

Fig. 5. Speed curve $-v$ in the RDE test cycle performed with a Fiat Idea drive cycle fragment of the urban drive section - RDE-U

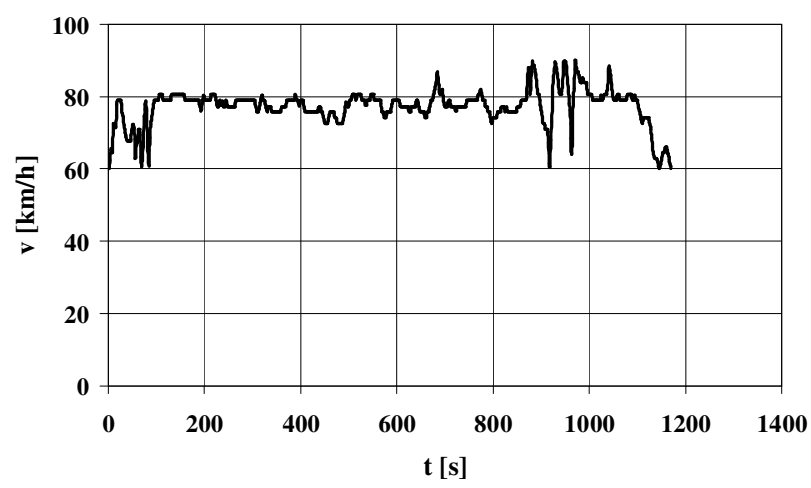

Fig. 6. Speed curve $-v$ in the RDE test cycle performed with a Fiat Idea drive cycle fragment of the rural drive section - RDE-R

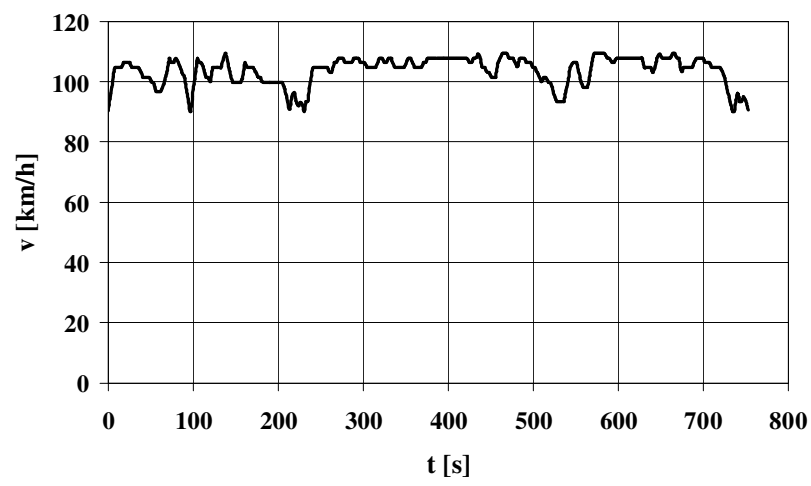

Fig. 7. Speed curve $-v$ in the RDE test cycle performed with a Fiat Idea drive cycle fragment of the highway drive section - RDE-H 
The Malta test was developed at the Poznan University of Technology for the purposes of simulating real driving conditions of a vehicle, similar to the traffic conditions in the NEDC test due to the criterion of the mean vehicle speed and the road traveled by the vehicle relating to different driving conditions [1].

The choice of exhaust emission tests in real operating conditions done in accordance with the RDE procedure was dictated by the fact that this is a test required by the Euro $6 \mathrm{~d}$ standard - this type of vehicle testing is currently preferred in terms of their ecological properties regarding the exhaust emission results $[8,9,16]$.

The RDE test was performed in line with the procedures set out by the Commission Regulation (EU) 2016/427 [8, 9, $16]$.

The RDE test includes driving in urban and rural areas as well as on highways or motorways. The whole drive cycle across different areas with varying speed limits takes place continuously. The rural drive section may be interrupted by short periods of urban driving if urban areas are on the route. Driving on highways and on the motorway may interrupt short driving periods in urban or rural areas.

The Dynoroad $120 \mathrm{~kW}$ AVL engine dynamometer station was used for the stationary engine tests. This station, equipped with a three-phase asynchronous electric motor, can be used to test the internal combustion engine in dynamic operating conditions. The dynamometer software enables simulation of the internal combustion engine operating conditions corresponding to its operation in the real vehicle drive conditions. The ISAC 400 software interface installed at the stand enables defining parameters for a drive test. As a result, it was possible to perform engine tests by simulating the conditions equivalent to those in the NEDC and Malta tests. A Portable Emission Measurement System (PEMS) was used to measure the exhaust emissions and fuel consumption. The exhaust gas analysis was performed with the Semtech DS analyzer. The analyzer meets the ISO 1065 requirements in the field of exhaust emissions testing with a PEMS systems. Semtech DS is equipped with the following measuring modules:

- FID (Flame Ionization Detector) - to measure hydrocarbons emission,

- NDUV (Non-Dispersive Ultraviolet) analyzer - using UV light to measure the emission of nitrogen oxides,

- NIDR (Non-Dispersive Infrared) analyzer - using IR light to measure the emission of carbon monoxide and carbon dioxide,

- Electrochemical analyzer to measure the oxygen content. In addition to measuring the exhaust emissions, the Semtech DS analyzer also allows the measurement of exhaust mass flow rates.

Measurement of particulate matter was performed with a TSI 3090 EPSS $^{\text {тм }}$ (Engine Exhaust Particle Sizer ${ }^{\text {TM }}$ Spectrometer) enabling, among others determining the particle diameter distribution.

Emission values in dynamic conditions were recorded at a frequency of $10 \mathrm{~Hz}$.

Preliminary tests were performed on the engine dynamometer, aimed at assessing the dependence of mass and number of solid particles. The tests were carried out in dy- namic conditions corresponding to the NEDC test simulation. Results of the data analysis have indicated that $90 \%$ of all emitted solid particles constitute only about $20 \%$ of the total mass of all solid particles emitted. About $90 \%$ of all particles contained in the flue gas have a diameter of less than $50 \mathrm{~nm}$, while the increase in particle mass is noticeable only for diameters greater than $50 \mathrm{~nm}$. The size range accounting for $80 \%$ of the mass of solid particles corresponds only to $10 \%$ of their total number (the largest particles from $50 \mathrm{~nm}$ to 200 $\mathrm{nm}$ in diameter). The results of these analyses were used as justification for measuring only of the number of solid particles (and not their mass) during the tests, which makes it also possible to record the particle emission intensity over time in dynamic engine operating conditions [13, 14].

The equipment used for engine tests, both for the engine dynamometer tests and in the real driving conditions, provided results of the mean road emission of exhaust components in the drive cycles, such as: carbon monoxide, hydrocarbons, nitrogen oxides and carbon dioxide and the mean number of particles.

\section{Results and analysis}

Figures 8-12 show the mean road exhaust emissions in each test and the number of particulates.

The strong relation between the mean road emissions value of gaseous exhaust components and the mean particle number road emission value for each test cycle is clearly visible.

In most cases, more dynamic properties of test drives favor higher values of the parameters tested. This is most

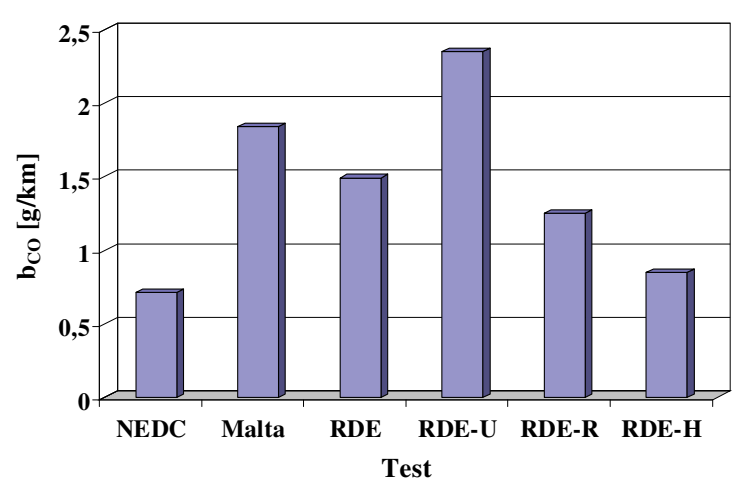

Fig. 8. Mean carbon monoxide road emissions $-\mathrm{b}_{\mathrm{CO}}$ in each of the test cycles

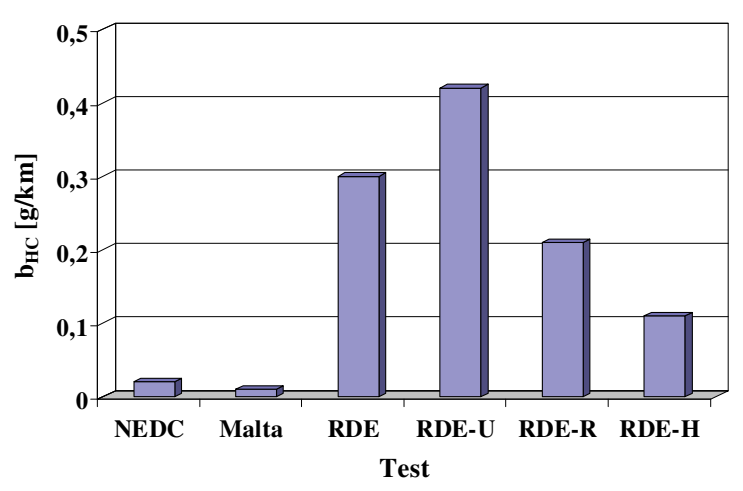

Fig. 9. Mean hydrocarbons road emissions $-b_{\mathrm{HC}}$ in each of the test cycles 


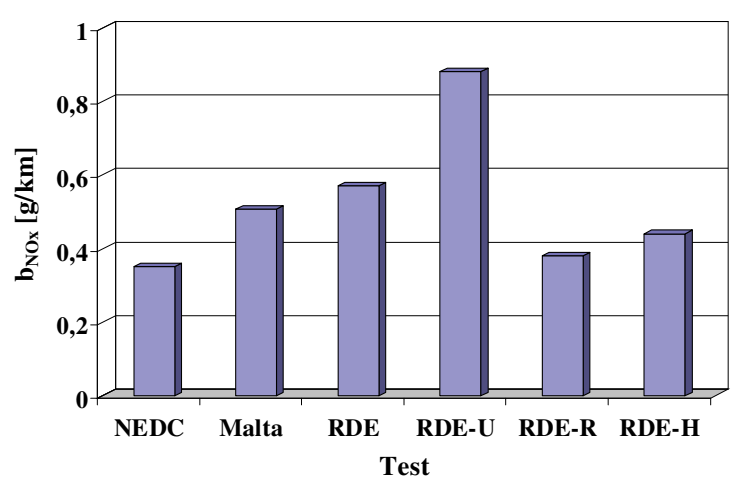

Fig. 10. Mean nitrogen oxides road emissions $-b_{\mathrm{NOx}}$ in each of the test cycles

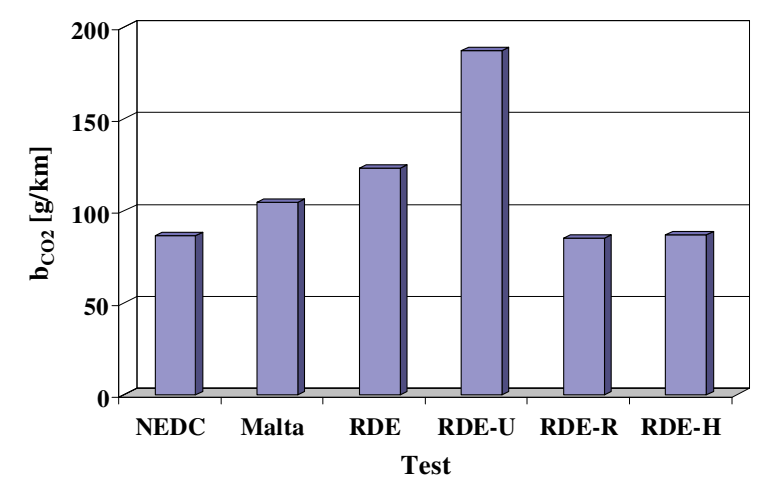

Fig. 11. Mean carbon dioxide road emissions $-\mathrm{b}_{\mathrm{CO} 2}$ in each of the test cycles

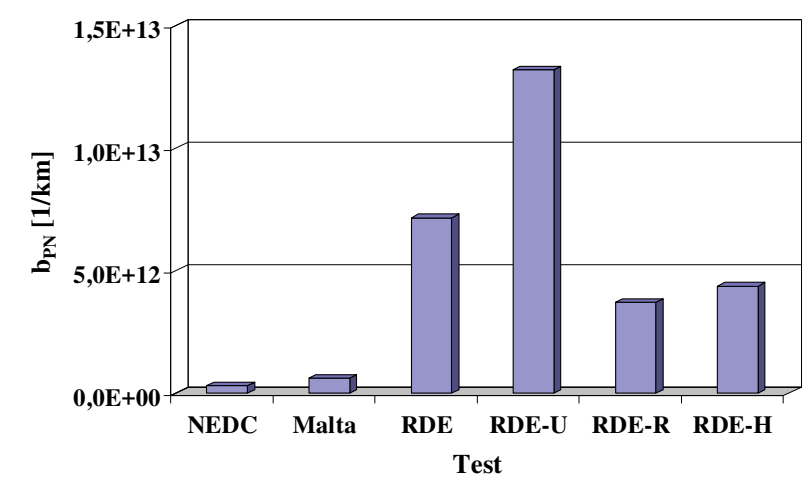

Fig. 12. Mean particle number road emissions $-b_{P N}$ in each of the test cycles

clearly visible for the particle number road emission and - to a slightly lesser degree - for the road hydrocarbons emissions. In these cases the real driving conditions correspond to much higher values of the examined emission quantities.

The emission characteristics for carbon dioxide and nitrogen oxides are the least affected by the dynamic conditions, which differ significantly in the performed test cycles. This is understandable. Carbon dioxide emissions are directly related to fuel consumption, and - as is known fuel consumption is much less sensitive to engine operating conditions than exhaust emissions other than carbon dioxide $[2-7,12]$. In the case of nitrogen oxides, the mean engine load [2-7, 12] plays a greater role than the occurrence of dynamic operating conditions. The differences in the test results for NEDC and Malta tests, which are similar in terms of the vehicle's mean speed, especially in the case of carbon monoxide, are more unexpected - this is probably the result of differences in the dynamic properties of both tests.

In order to perform deeper analysis of the obtained research results, it is necessary to consider differences in the used research tests properties. For this purpose, two nondimensional characteristics of speed curves, whose implementation is the analyzed tests, were determined.

The mean vehicle drive speed value $-\mathrm{v}_{\mathrm{AV}}$ is:

$$
\mathrm{v}_{\mathrm{AV}}=\mathrm{AV}[\mathrm{v}(\mathrm{t})]
$$

where: $\mathrm{AV}$ - the mean value operator, $\mathrm{t}$ - time.

The mean vehicle speed is characterized primarily by the engine load.

The mean of the absolute value of the velocity and acceleration product is:

$$
A=A V[\operatorname{Mod}[v(t) \cdot a(t)]]
$$

where: Mod - absolute value operator.

The mean absolute value of the velocity and acceleration product is proportional to the mean useful power of the vehicle in dynamic operating conditions $[2,4]$. It is a quantity that characterizes the dynamic properties of the speed characteristic.

Figures 13 and 14 show the mean speed value and the mean absolute value of the velocity and acceleration product in individual tests.

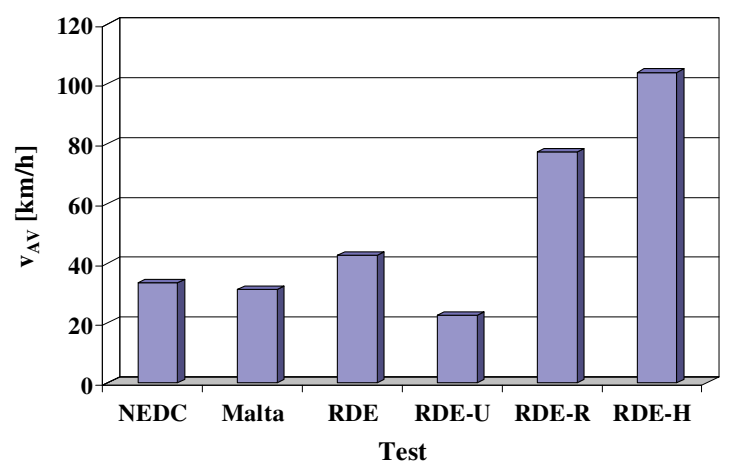

Fig. 13. Mean speed $-v_{A V}$ in each of the test cycles

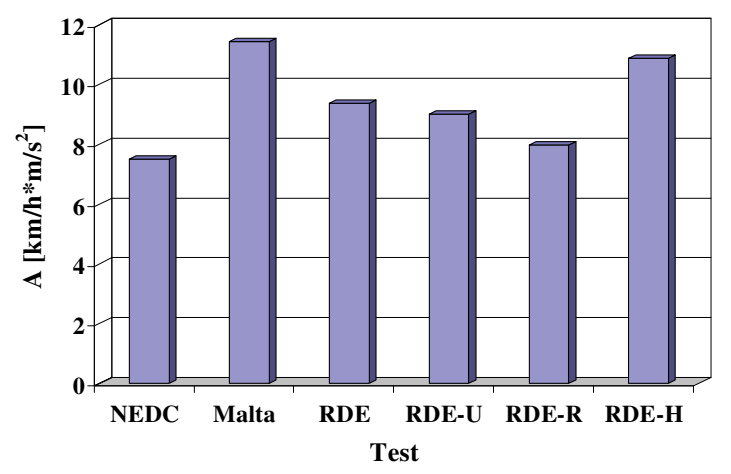

Fig. 14. The mean absolute value of the velocity and acceleration product - A in each of the test cycles 
The mean vehicle speed in the NEDC and Malta tests is similar (in accordance with the assumptions of the Malta test synthesis) and - then - in the RDE test.

In the case of the mean absolute value of the velocity and acceleration product, a large difference is clearly visible for tests whose mean speed is similar: NEDC and Malta. This is the result of the more dynamic properties of the Malta test, created with an accurate simulation in the time domain, in relation to the dynamic properties of the NEDC test, created using the speed characteristic synthesis according to the similarity of non-dimensional characteristics with those of the simulated process.

Figure 15 presents the relation between the two considered non-dimensional characteristics of the performed test cycles.

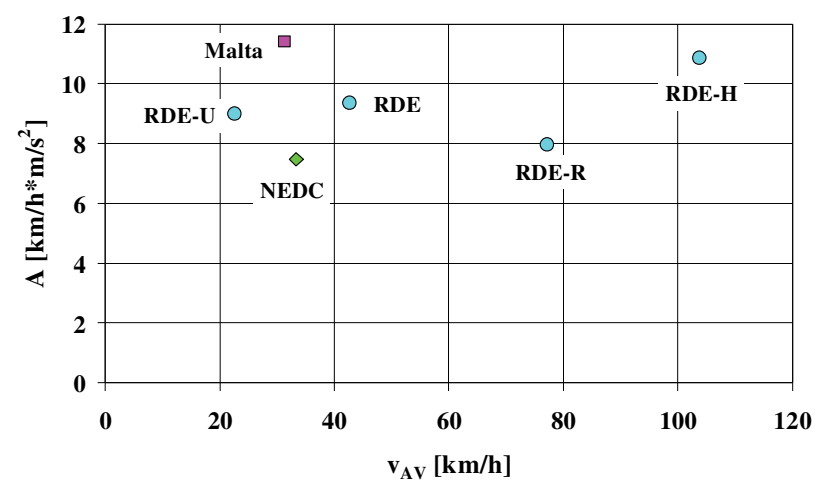

Fig. 15. The relation between the mean absolute value of the velocity and acceleration product $-\mathrm{A}$ on the mean speed $-\mathrm{v}_{\mathrm{AV}}$ in each of the test cycles

This graph shows the difference between the properties of the NEDC and Malta tests.

Figures 16-20 show the relation between the mean road exhaust emissions, and the mean road particle number emission, and the vehicle mean speed in individual tests.

Characteristics for the tests: RDE, RDE-U, RDE-R and RDE-H were approximated with third degree polynomial, assuming the sum of squares as the approximation criterion.

It should be noted that there is a clear pattern for RDE tests [2-4, 6, 7], while for Malta and NEDC tests there are significant deviations from the characteristics determined for the RDE tests.

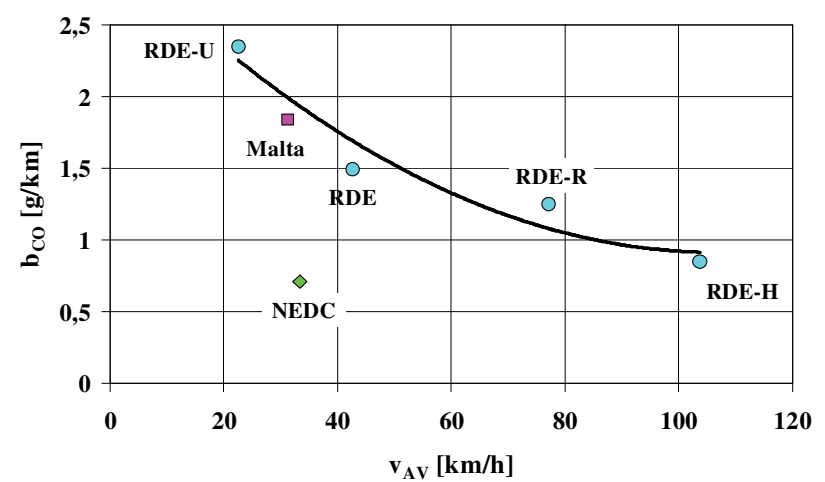

Fig. 16. The relation between the mean road emission of carbon monoxide $-\mathrm{b}_{\mathrm{CO}}$ and the mean vehicle speed $-\mathrm{v}_{\mathrm{AV}}$ in each test cycle

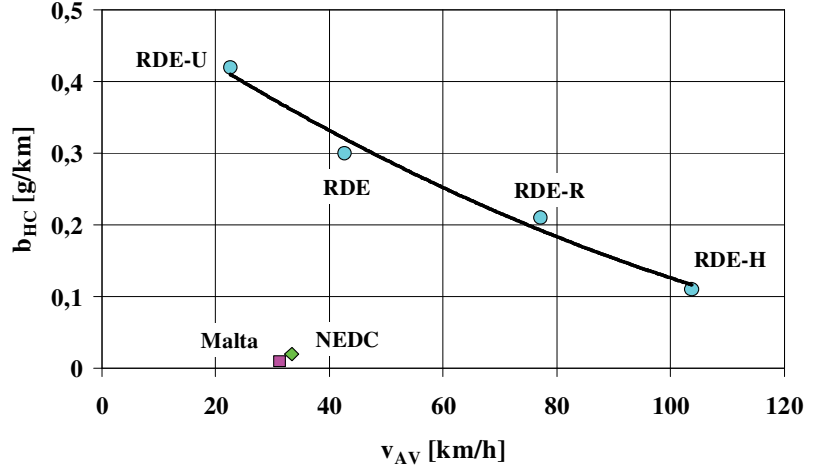

Fig. 17. The relation between the mean road emission of hydrocarbons $b_{\mathrm{HC}}$ and the mean vehicle speed $-\mathrm{v}_{\mathrm{AV}}$ in each test cycle

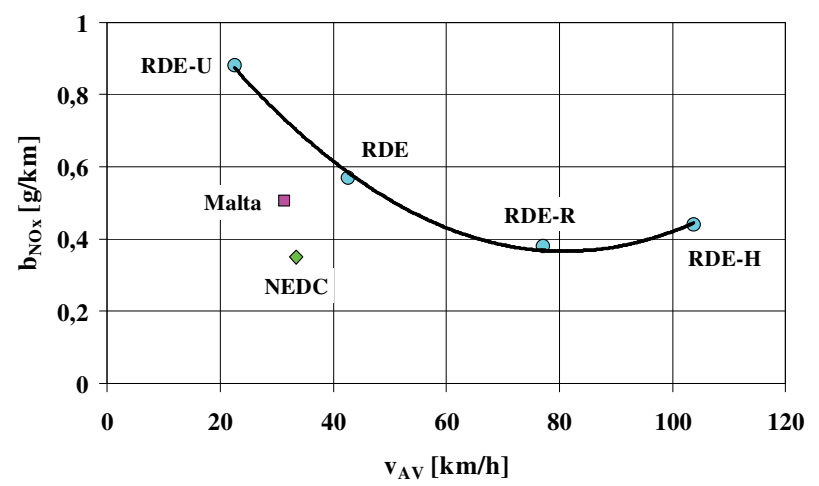

Fig. 18. The relation between the mean road emission of nitrogen oxides $\mathrm{b}_{\mathrm{NOx}}$ and the mean vehicle speed $-\mathrm{v}_{\mathrm{AV}}$ in each test cycle

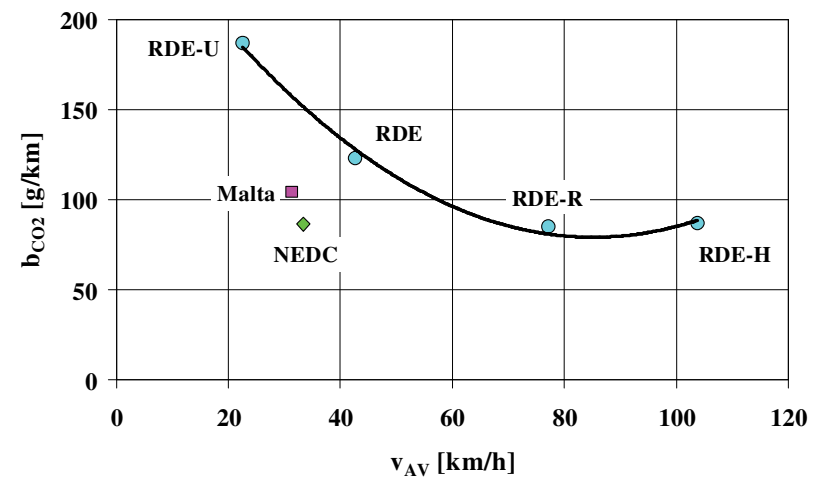

Fig. 19. The relation between the mean road emission of carbon dioxide $\mathrm{b}_{\mathrm{CO} 2}$ and the mean vehicle speed $-\mathrm{v}_{\mathrm{AV}}$ in each test cycle

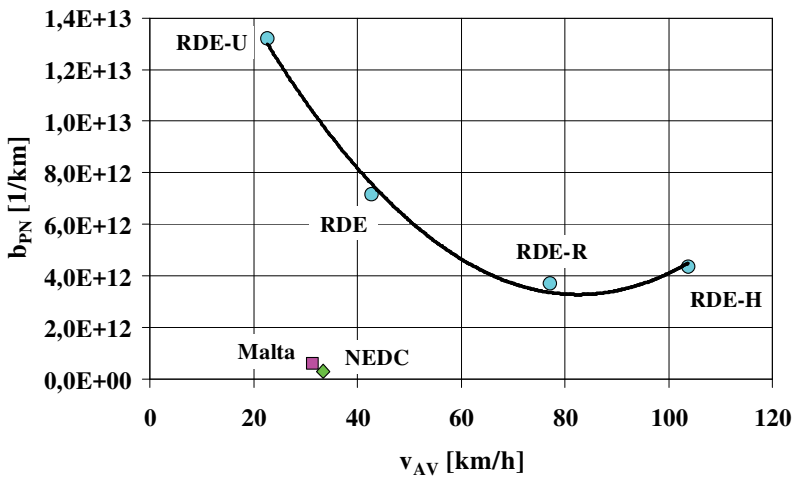

Fig. 20. The relation between the mean road emission of particles $-b_{\mathrm{PN}}$ and the mean vehicle speed $-\mathrm{v}_{\mathrm{AV}}$ in each test cycle 
To assess the impact of the driving conditions modeled by individual tests (in NEDC and Malta tests relative to the analyzed values in RDE tests) on the mean road exhaust emission and the mean particle number, the metric described in [10] was used - the relative mean difference in values of $x_{i}$ and $x_{i R D E}$ :

$$
\delta=2 \cdot \frac{\mathrm{x}_{\mathrm{i}}-\mathrm{x}_{\mathrm{iRDE}}}{\mathrm{x}_{\mathrm{i}}+\mathrm{x}_{\mathrm{iRDE}}}
$$

where: $\mathrm{x}_{\mathrm{i}}$ - mean road emission of individual exhaust components or mean road emission of the number of particle, $\mathrm{i}=\mathrm{NEDC}$, Malta, $\mathrm{x}_{\mathrm{i} \text { RDE }}$ - approximate value of the RDE tests characteristic.

The mean road emission of individual exhaust components and the mean road particle number emission in the $\mathrm{RDE}$ test is modeled as the value of the characteristic approximated based on test results in RDE, RDE-U, RDE-R and $\mathrm{RDE}-\mathrm{H}$ tests for mean vehicle speed equal to the mean speed in the other tests: NEDC and Malta (example in Fig. 21).

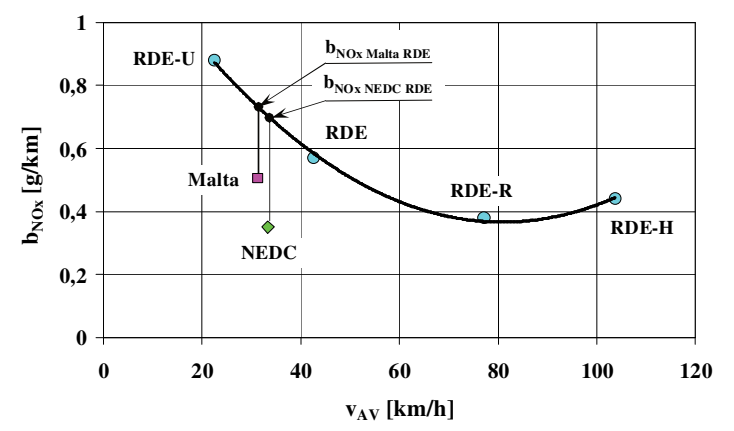

Fig. 21. Schematic for determining the approximate characteristic value from the results of RDE, RDE-U, RDE-R and RDE-H tests for mean

vehicle speed equal to the mean speed in the NEDC and Malta tests

The relative difference of the mean road emission of individual exhaust components and the mean number of particles emitted for the NEDC test and the modeled values from the RDE test, as well as for the Malta test and the modeled values from the RDE test have been shown in Figs 22 and 23.

The most impact was found for NEDC and Malta tests compared to RDE tests on the mean hydrocarbons and particle emissions, and the least impact was found on: nitrogen

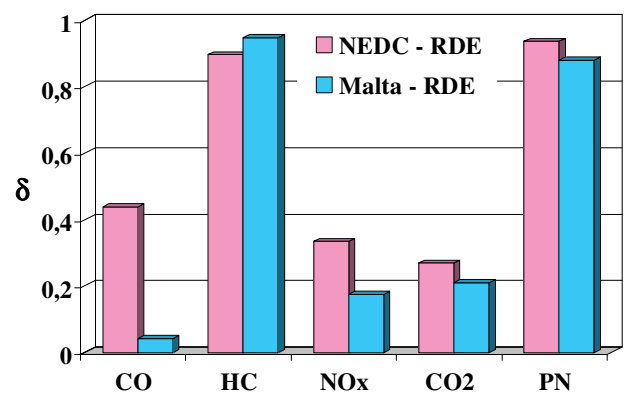

Fig. 22. Relative difference of the mean road emission of individual gaseous pollutants and the mean particle number $-\delta$ for the NEDC test and the modeled values from the RDE test, as well as for the Malta test and the modeled values from the RDE test

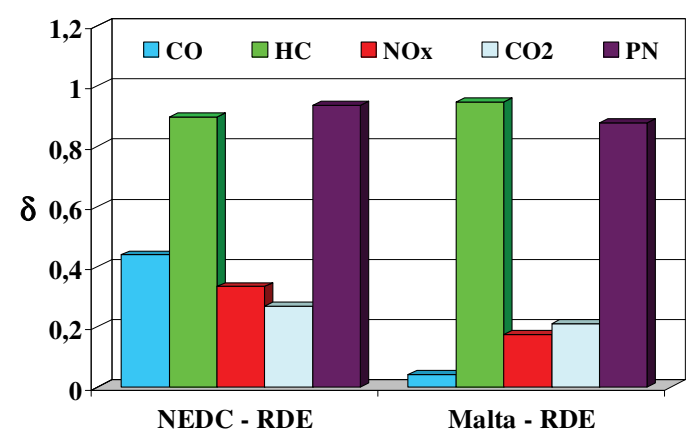

Fig. 23. Relative difference of the mean road emission of individual gaseous pollutants and the mean particle number $-\delta$ for the NEDC test and the modeled values from the RDE test, as well as for the Malta test and the modeled values from the RDE test

oxides and carbon dioxide road emissions. There is also a larger difference of the non-dimensional characteristics values tested for the NEDC test than for the Malta test in relation to the values for RDE tests.

\section{Conclusions}

The tests carried out confirm a large dependence of exhaust emission values on the internal combustion engine's operating conditions. These conditions are determined by the vehicle speed curve in the drive cycle, hence the selection of driving tests that simulate real operating conditions on the road is important for assessing the ecological properties of automotive internal combustion engines with regard to the exhaust emissions.

The average road exhaust emission in drive test cycles created by accurately simulating the time domain is clearly greater than in tests developed as a synthesis of the speed curve based on the similarity of non-dimensional characteristics of speed characteristic, as shown by this research. The main reason for this outcome are the dynamic properties of tests created from the drive speed data simulation in the time domain [3]. The most visible tendency is the exhaust emissions sensitivity to the dynamic conditions of engine operation in the case of hydrocarbons and solid particles, followed by carbon monoxide. In the case of nitrogen oxides, the dominant factor is the mean engine load, determined by the mean vehicle speed.

Tests created based on accurate speed simulation in the time domain, that are more difficult to perform regarding the exhaust emission from internal combustion engine's operating conditions, confirm the validity of adopting such a tendency in the selection of tests in type approval procedures, an example of which is the WLTC test.

Conclusions based on the article research results concern the latest generation engine. This fact may be the reason for the greater sensitivity of engine exhaust emissions to the changes in operating conditions. It is therefore appropriate to extend the scope of research in the following directions:

- comparative studies of newer generation spark and compression ignition engines,

- engine tests in the WLTC test cycle and the implementation of pseudorandom car speed curves $[5,7,11,15]$,

- repeating the engine tests, which will allow to evaluate the repeatability of the test results $[3,5,6]$. 


\section{Bibliography}

[1] ANDRYCH-ZALEWSKA, M. Wpływ katalizatora wewnętrznego na emisję spalin w stanach pracy silnika o zapłonie samoczynnym odpowiadających jego użytkowaniu trakcyjnemu. Rozprawa doktorska. Poznań 2018.

[2] BUWAL (Bundesamt für Umwelt, Wald und Landschaft), INFRAS AG (Infrastruktur-, Umwelt- und Wirtschaftsberatung). Luftschadstoffemissionen des Strassenverkehrs 1950 2010, BUWAL-Bericht 1995, 255.

[3] CHŁOPEK, Z. et al. Modelling of motor vehicle operation for the evaluation of pollutant emission and fuel consumption. Combustion Engines. 2017, 171(4), 156-163.

[4] CHŁOPEK, Z., SZCZEPAŃSKI, K. Modelling of vehicle velocity in the inventory of pollutant emission. Machine Dynamics Research. 2017, 41(2), 119-139.

[5] CHŁOPEK, Z. Synthesis of driving cycles in accordance with the criterion of similarity of frequency characteristics. Eksploatacja i Niezawodnosc - Maintenance and Reliability. 2016, 18(4), 572-577, doi:10.17531/ein.2016.4.12.

[6] CHŁOPEK, Z. et al. Assessment of the impact of dynamic states of an internal combustion engine on its operational properties. Eksploatacja i Niezawodnosc-Maintenance and Reliability. 2015, 17(1), 35-41.

[7] CHŁOPEK, Z., LASKOWSKI, P. Pollutant emission characteristics determined using the Monte Carlo Method. Eksploatacja i Niezawodnosc - Maintenance and Reliability. 2009, 2(42), 42-51.

[8] Commission Regulation (EU) 2016/427 of 10 March 2016 amending Regulation (EC) No. 692/2008 as regards emissions from light passenger and commercial vehicles (Euro 6), Verifying Real Driving Emissions, Official J. European Union, L 82, 2016.
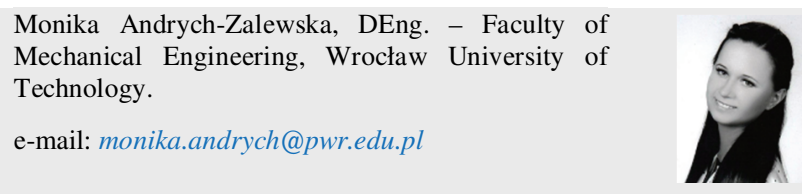

Prof. Zdzisław Chłopek, DSc. DEng. - Faculty of Automotive and Construction Machinery Engineering, Warsaw University of Technology.

e-mail: Zdzislaw.Chlopek@pw.edu.pl
[9] Commission Regulation (EU) 2016/646 of 20 April 2016 amending Regulation (EC) No. 692/2008 as regards emissions from light passenger and commercial vehicles (Euro 6), Verifying Real Driving Emissions, Official J. European Union, L 109, 2016.

[10] HAUSDORFF, F. Dimension und äusseres Mass. Mathematische Annalen. 1918, 79(1-2), 157-179.

[11] LEE, T.-K., FILIPI, Z.S. Synthesis of real-world driving cycles using stochastic process and statistical methodology. International Journal of Vehicle Design. 2011, 57(1), 17-36.

[12] MERKISZ, J. et al. Exhaust emission tests from non-road vehicles conducted with the use of PEMS analyzers. Eksploatacja i Niezawodnosc - Maintenance and Reliability. 2013, 15(4), 364-368.

[13] MERKISZ, J., PIELECHA, J. Nanoparticle emissions from combustion engines. Springer Tracts on Transportation and Traffic. 2015, 8, 139.

[14] PIELECHA, J. Identyfikacja parametrów cząstek stałych z silników spalinowych. Rozprawa habilitacyjna, Rozprawy nr 467. Wydawnictwo Politechniki Poznańskiej. Poznań 2012.

[15] SOUFFrAN, G., MIÈGEVILLE, L., GUÉRIN, P. Simulation of real-world vehicle emissions using a stochastic Markov model for optimal design purposes. IREENA Laboratory, University of Nantes, Saint-Nazaire, France 978-161284-246-9/11, 2011 IEEE.

[16] Worldwide emission standards. Passenger cars and light duty vehicles. Delphi. Innovation for the real world. 2016/2017.

Prof. Jerzy Merkisz, DSc., DEng. - Faculty of Transport Engineering, Poznan University of Technology.

e-mail: Jerzy.Merkisz@put.poznan.pl

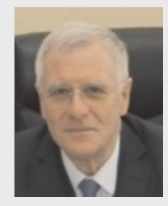

Prof. Jacek Pielecha, DSc., DEng. - Faculty of Transport Engineering, Poznan University of Technology.

e-mail: Jacek.Pielecha@put.poznan.pl 